\title{
NONLOCAL PROBLEMS FOR DELAY \\ INTEGRODIFFERENTIAL EQUATIONS IN BANACH SPACES
}

\begin{abstract}
ZUOMAO YAN
Abstract. In this paper we study the existence of mild solutions for a class of first-order delay integrodifferential equations with nonlocal condition in a Banach space. The results are established by the application of the theory of resolvent operators, the contraction mapping principle and the Schaefer theorem. An example is presented in the end to show the applications of the obtained results.
\end{abstract}

Mathematics subject classification (2010): 34K30, 34A60, 34G20.

Keywords and phrases: delay integrodifferential equations, fixed point theorem, nonlocal conditions.

\section{REFERENCES}

[1] S. Aizicovici, M. MCKiBBen, Existence results for a class of abstract nonlocal Cauchy problems, Nonlinear Anal., 39 (2000), 649-668.

[2] L. BYSZEWSKI, Theorems about the existence and uniqueness of solutions of a semilinear evolution nonlocal Cauchy problem, J. Math. Anal. Appl., 162 (1991), 494-505.

[3] L. ByszewsKi, H. AKCA, Existence of solutions of a semilinear functional-differential evolution nonlocal problem, Nonlinear Anal., 34 (1998), 65-72.

[4] M. Benchohra, E. Gatsori, J. Henderson, S.K. Ntouyas, Nondensely defined evolution impulsive differential inclusions with nonlocal conditions, J. Math. Anal. Appl., 286 (2003), 307-325.

[5] K. Balachandran, J. Y. Park, M. Chandrasekaran, Nonlocal Cauchy problems for delay integrodifferential equations of sobolev type in Banach spaces, Appl. Math. Lett., 15 (2002), 845-854.

[6] M. Benchohra, E. P. GATSORI AND S. K. NTOUYAS, Controllability results for semilinear evolution inclusions with nonlocal conditions, J. Optim. Theory Appl., 118 (2003), 493-513.

[7] M. Chandrasekaran, Nonlocal Cauchy problem for quasilinear integrodifferential equations in Banach spaces, Electron. J. Diff. Eqns., 2007 (2007), 1-6.

[8] K. Deng, Exponential decay of solutions of semilinear parabolic equations with nonlocal initial conditions, J. Math. Anal. Appl., 179 (1993), 630-637.

[9] J. Dugundu And A. GRanas, Fixed point theory, Monografie Mat. PWN, Warsaw, 1982.

[10] R. Grimmer And J.H. LiU, Integrated semigroups and integrodifferential equations, Semigroup Forum, 48 (1994), 79-95.

[11] R. GRIMmeR, Resolvent operators for integral equations in Banach space, Trans. Amer. Math. Soc., 48 (1982), 333-349.

[12] J. H. LiU AND K. EZZINBI, Non-autonomous integrodifferential equations with nonlocal conditions, J. Integral Equ. Appl., 15 (2003), 79-93.

[13] Y. LIN, J.H. LiU, Semilinear integrodifferential equations with nonlocal Cauchy problem, Nonlinear Anal., 26 (1996), 1023-1033. 
[14] J. Liang, J.H. LiU, T.J. XIAO, Nonlocal Cauchy problems governed by compact operator families, Nonlinear Anal., 57 (2004), 183-189.

[15] S.K. NTOUYAs, P.CH. Ts Amatos, Global existence for semilinear evolution equations with nonlocal conditions, J. Math. Anal. Appl., 210 (1997), 679-687.

[16] J. PRUSS, On resolvent operators for linear integrodifferential equations of Volterra type, J. Integral Equations, 5 (1983), 211-236.

[17] K.Yosida, Functional Analysis, sixth ed., Springer, Berlin, 1980. 